\title{
IMPLEMENTASI KEPERAWATAN ISLAMI PERAWAT PELAKSANA TERHADAP PASIEN SAFETY DI RUMAH SAKIT MUHAMMADIYAH BANDUNG TAHUN 2017
}

\author{
Rahmat \\ Program Studi Keperawatan Universitas Muhammadiyah Jakarta \\ E-mail : syifataini.sastro17@gmai.com
}

\begin{abstract}
Abstrak
Islam telah mengajarkan tentang pelayanan kesehatan yang memberikan pelayanan komprehensif baik bio-psiko-sosio-kultural maupun spritual yang ditujukan kepada individu maupun masyarakat, dengan pemikiran yang hipotetik tentang pelayanan kesehatan yang Islami dapat mewujudkan pelayanan prima di rumahsakit-rumahsakit Islam. Patien safety telah menjadi isu dunia yang perlu mendapat perhatian bagi sistem pelayanan kesehatan. Patien safety merupakan prinsip dasar dari pelayanan kesehatan yang memandang bahwa keselamatan merupakan hak bagi setiap pasien dalam menerima pelayanan kesehatan. Metode: jenis penelitian quasi eksperimen dengan rancangan adalah pretest-posttest with control group design fase, dengan 60 sample yang dibagi dua kelompok yang satu sebagai kelompok kontrol dan satu sebagai kelompok intervensi. Hasil: tahap pertama: untuk melihat penerapan patien safety oleh perawat pelaksana di 4 ruangan. Tahap ke dua penerapan modul keperawatan islami terhadap kelompok intervensi, tahap ke 3 akan ada pengaruh modul pelayanan islami terhadap patien safety.uji statistic didapat hahwa Sig $0,000<0,05$ ada perbedaan yang signifikan pelaksanaan patien safety sesudah dilakukan intervensi pada kelompok intervensi. Uji general linier model menunjukkan ada beda kelompok intervensi pre-test dan post-test secara umum tidak ada perbedaan pencapaian patien safety antar kedua kelompok. Hasil tes tidak ada perbedaan rata rata selisih skor pencapaian kompetensi antar keempat pengukuran yaitu $\mathrm{p}=0,230(\mathrm{P}<\alpha)$ : hasil uji statistic didapat.
\end{abstract}

Kata Kunci : Keperawatan Islami, Patient Safety, pelayanan Islami, Pelatihan.

\section{Latar Belakang}

Paradigma pelayanan di dunia kesehatan kini sudah berubah, dari pandangan lama "pemberi jasa pelayanan" yang merasa sangat berjasa kepada pasien, berubah menjadi "pelayan jasa kesehatan" yang menganggap pasien sebagai pelanggan (customer oriented) (Widajat, 2008). Rumah sakit juga mengalami transformasi besar, situasi global dan kompetitif pun tak terelakkan. Konsep manajemen yang jelas dibutuhkan untuk membuat perkembangan rumah sakit di Indonesia berjalan dengan cepat. Konsep manajemen inilah yang akan mengantarkan rumah sakit untuk meningkatkan mutu pelayanan yang memperhatikan tuntutan 
JURNAL ILMU KESEHATAN BHAKTI HUSADA:

HEALTH SCIENCES JOURNAL, Vol. 09 No. 01, JUNI 2018

DOI: https://doi.org/10.34305/jikbh.v9i1.57

masyarakat. Konsumen kini tidak lagi mempertimbangkan fungsi, harga, cita rasa ataupun prestise, namun juga mempertimbangkan nilai baik buruk, halal haram yang berhubungan dengan keyakinannya. Mayoritas penduduk muslim di Indonesia hingga mencapai 91,94\% jelas menjadi alasan kuat bagi bisnis berbasis islam termasuk pula pelayanan kesehatan dan rumah sakit. Namun hingga saat ini jumlah rumah sakit islam atau rumah sakit bernuansa islam yang beroperasi memberikan pelayanan kesehatan masih jauh dari memadai (Ayuningtyas, 2008)

Walaupun jumlah rumah sakit yang bernuansa islam masih belum banyak, namun rumah sakit islam harus tetap meningkatkan mutu pelayanan agar dapat bertahan di kompetesi global dan pemenuhan kebutuhan pelayanan kesehatan islami untuk masyarakat. Terdapat lima aspek pelayanan kesehatan islami yaitu sikap dan perilaku petugas yang islami, fasilitas dan sarana pelayanan kesehatan islami, prosedur tata cara atau mekanisme pelayanan kesehatan islami, suasana pelayanan kesehatan islami serta pembiayaan pelayanan kesehatan islami (Ayuningtyas, 2008).

Islam telah mengajarkan tentang pelayanan kesehatan yang memberikan pelayanan komprehensif baik bio-psikososio-kultural maupun spritual yang ditujukan kepada individu maupun masyarakat. Kegiatan medis dan keperawatan dalam Islam merupakan manifestasi dari fungsi manusia sebagai khalifah dan hamba Allah dalam melaksanakan kemanusiaannya, menolong manusia lain yang mempunyai masalah kesehatan dan memenuhi kebutuhan dasarnya baik aktual maupun potensial. Permasalahan klien (pasien) dengan segala keunikannya tersebut harus dihadapi dengan pendekatan silaturrahmi (interpersonal) dengan sebaik-baiknya
Ciptaan disebarluaskan di bawah

Lisensi Creative Commons Atribusi-

NonKomersial-BerbagiSerupa 4.0

Internasional. Internasional.

didasari dengan iman, ilmu dan amal. Untuk dapat memberikan asuhan medik dan asuhan keperawatan kepada pasien, dokter dan perawat dituntut memiliki ketrampilan intelektual, interpersonal, tehnikal serta memiliki kemampuan berdakwah amar ma'ruf nahi mungkar.

Melaksanakan pelayanan kesehatan profesional yang Islami terhadap individu, keluarga, kelompok maupun masyarakat dengan berpedoman kepada kaidah-kaidah Islam, medik dan keperawatan yang mencakup: (1) menerapkan konsep, teori dan prinsip dalam keilmuan yang terkait dengan asuhan medik dan asuhan keperawatan dengan mengutamakan pedoman pada Al-Qur'an dan Hadits, (2) melaksanakan asuhan medik dan asuhan keperawatan dengan menggunakan pendekatan Islami melalui kegiatan kegiatan pengkajian yang berdasarkan bukti (evidence-based health care), (3) mempertanggungjawabkan atas segala tindakan dan perbuatan yang berdasarkan bukti (evidence-based healthcare), (4) berlaku jujur, ikhlas dalam memberikan pertolongan kepada pasien baik secara individu, keluarga, kelompok maupun masyarakat dan semata-mata mengharapkan ridho Allah, (5) bekerjasama dengan tenaga kesehatan lainnya untuk meningkatkan mutu pelayanan kesehatan dan menyelesaikan masalah pelayanan kesehatan yang berorientasi pada asuhan medik dan asuhan keperawatan yang berdasarkan bukti (evidence-based health care). Praktek pelaksanaan evidence-based healthcare adalah integrasi kemampuan klinis individual dengan bukti klinis eksternal yang terbaik dan yang tersedia dari penelitian klinis yang sistematis (akurasi dan presisi tes diagnostik, kekuatan tanda-tanda prognosis, kemangkusan serta keamanan terapi, rehabilitasi dan tindakan prevensi). (Rusdi Lamsudin 2005) 
Ciptaan disebarluaskan di bawah

Lisensi Creative Commons Atribusi-

NonKomersial-BerbagiSerupa 4.0 Internasional. Internasional.
Perawat pelaksana memiliki peran besar dalam pelaksanaan patient safety. Peran tersebut di antaranya mencegah terjadinya kesalahan pengobatan, melaporkan kejadian, mendidik diri sendiri dan sesama perawat, memberikan rekomendasi tentang perubahan dalam prosedur dan kebijakan, melibatkan dalam mengidentifikasi masalah (Ramsey, 2005). MNT (2009) mengatakan bahwa perawat memegang peran kunci dalam memenuhi tujuan keselamatan pasien dalam hal obatobatan, komunikasi dan keamanan pasien. Peran tersebut menjadi tantangan bagi perawat.

Patien safety telah menjadi isu dunia yang perlu mendapat perhatian bagi sistem pelayanan kesehatan. Patien safety merupakan prinsip dasar dari pelayanan kesehatan yang memandang bahwa keselamatan merupakan hak bagi setiap pasien dalam menerima pelayanan kesehatan (Permenkes RI, 2011). Patient safety juga dapat diartikan sebagai suatu keadaan pasien yang bebas dari cidera yang tidak seharusnya terjadi atau bebas dari cidera yang berisiko dapat terjadi (KPP-RS, 2008).

\section{Metode Penelitian}

Penelitian ini merupakan jenis penelitian quasi eksperimen dengan rancangan yang digunakan adalah pretestposttest with control group design, yaitu terdapat dua kelompok yang satu sebagai kelompok kontrol dan satu sebagai kelompok intervensi. Rancangan penelitian ini kelompok intervensi menerima perlakuan/intervensi sedangkan pada kelompok kontrol tidak dilakukan intervensi. Sebelum kelompok intervensi diberi intervensi, dilakukan pengukuran awal ( pre test) pada kelompok intervensi dan kelompok control untuk menentukan kemampuan awal. Selanjutnya pada kelompok intervensi dilakukan intervensi sesuai dengan yang direncanakan, sedangkan pada kelompok control tidak dilakukan intervensi. Kelompok intervensi diberikan intervensi berupa penerapan pelatihan keperawatan Islami.

Tabel 1. Hasil Pengukuran Patient Safety Kelompok Intervensi dan Kontrol

\begin{tabular}{|c|c|c|c|c|}
\hline \multirow[b]{2}{*}{ Variabel } & \multicolumn{2}{|c|}{ Kelompok Intervensi } & \multicolumn{2}{|c|}{ Kelompok Kontrol } \\
\hline & $\begin{array}{c}\text { Frekuensi } \\
\text { (orang) }\end{array}$ & $\begin{array}{c}\text { Persentase } \\
(\%)\end{array}$ & $\begin{array}{c}\text { Frekuensi } \\
\text { (orang) }\end{array}$ & $\begin{array}{c}\text { Persentase } \\
(\%)\end{array}$ \\
\hline \multicolumn{5}{|c|}{$\begin{array}{l}\text { 1. Patient safety } \\
\text { pengukuran ke } 1\end{array}$} \\
\hline Kurang & . & - & - & - \\
\hline Cukup & 10 & 33,3 & 13 & 43,3 \\
\hline Baik & 20 & 66,7 & 7 & 56,7 \\
\hline \multicolumn{5}{|c|}{$\begin{array}{l}\text { 2. Patient safety } \\
\text { pengukuran ke } 2\end{array}$} \\
\hline Kurang & 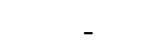 & - & - & - \\
\hline Cukup & 7 & 23,3 & 13 & 43,3 \\
\hline Baik & 23 & 76,7 & 7 & 56,7 \\
\hline \multicolumn{5}{|c|}{$\begin{array}{l}\text { 3. Patient safety } \\
\text { pengukuran ke } 3\end{array}$} \\
\hline Kurang & - & - & - & - \\
\hline Cukup & 8 & 26,7 & 13 & 43,3 \\
\hline Baik & 22 & 73,3 & 7 & 56,7 \\
\hline
\end{tabular}


Ciptaan disebarluaskan di bawah Lisensi Creative Commons AtribusiNonKomersial-BerbagiSerupa 4.0 Internasional. Internasional.

\begin{tabular}{ccccc}
\hline Variabel & \multicolumn{2}{c}{ Kelompok Intervensi } & \multicolumn{2}{c}{ Kelompok Kontrol } \\
\cline { 2 - 5 } & $\begin{array}{c}\text { Frekuensi } \\
\text { (orang) }\end{array}$ & $\begin{array}{c}\text { Persentase } \\
(\%)\end{array}$ & $\begin{array}{c}\text { Frekuensi } \\
\text { (orang) }\end{array}$ & $\begin{array}{c}\text { Persentase } \\
(\%)\end{array}$ \\
\hline $\begin{array}{c}\text { 4. Patient safety } \\
\text { pengukuran ke 4 }\end{array}$ & & & & \\
Kurang & - & - & - & - \\
Cukup & 6 & 20 & 13 & 43,3 \\
Baik & 24 & 80 & 7 & 56,7 \\
\hline
\end{tabular}

Berdasarkan tabel menunjukkan pada kelompok intervensi seluruhnya masuk dalam kategori baik yaitu sebesar $100 \%$, begitu pula pada kelompok kontrol seluruhnya masuk dalam kategori baik yaitu sebesar $100 \%$. Untuk patient safety pengukuran ke 1 pada kelompok intervensi sebagian besar masuk dalam kategori baik yaitu sebesar 66,7\%, sedangkan pada kelompok kontrol sebagian besar masuk dalam kategori cukup yaitu sebesar 43,3\%. Untuk patient safety pengukuran ke 2 pada kelompok intervensi sebagian besar masuk dalam kategori baik yaitu sebesar 76,7\%, sedangkan pada kelompok kontrol sebagian besar masuk dalam kategori cukup yaitu sebesar 43,3\%. Untuk patient safety pengukuran ke 3 pada kelompok intervensi sebagian besar masuk dalam kategori baik yaitu sebesar 73,3\%, sedangkan pada kelompok kontrol sebagian besar masuk dalam kategori cukup yaitu sebesar 43,3\%. Untuk patient safety pengukuran ke 4 pada kelompok intervensi sebagian besar masuk dalam kategori baik yaitu sebesar $80 \%$, sedangkan pada kelompok kontrol sebagian besar masuk dalam kategori cukup yaitu sebesar 43,3\%.

Tabel 2. Indikator Patient Safety

\begin{tabular}{clccc}
\hline No & \multicolumn{1}{c}{ Sub Varibel } & Skor & Total & \% \\
\hline $\mathbf{1}$ & Identifikasi Pasien & 663 & 720 & 92 \\
\hline $\mathbf{2}$ & Komunikasi Efektif & 345 & 480 & 72 \\
\hline $\mathbf{3}$ & Keamanan Obat & 259 & 360 & 72 \\
\hline $\mathbf{4}$ & Tepat lokasi \& pasien & 460 & 480 & 96 \\
\hline $\mathbf{5}$ & Pencegahan Resiko Infeksi & 295 & 360 & 82 \\
\hline $\mathbf{6}$ & Pencegahan Resiko Jatuh & 169 & 240 & 70
\end{tabular}

Berdasarkan hasil analisis pada tabel dapat disimpulkan bahwa indikator ketepatan lokasi pasien mendapatkan skor sebesar $96 \%$, indikator identifikasi pasien $92 \%$, indikator resiko infeksi $82 \%$, indikator keamanan obat $72 \%$, indikator komunikasi efektif $72 \%$ dan indikator resiko jatuh $70 \%$. 
DOI: https://doi.org/10.34305/jikbh.v9i1.57
Ciptaan disebarluaskan di bawah Lisensi Creative Commons AtribusiNonKomersial-BerbagiSerupa 4.0 Internasional. Internasional.

Tabel 3. Uji Beda Rata-Rata Pelaksanaan Sasaran Keselamatan Pasien, Sesudah Intervensi pada Kelompok Intervensi \& Kelompok Kontrol

\begin{tabular}{cccc}
\hline Kelompok & N & Rerata & Pvalue \\
\cline { 1 - 2 } Eksperimen & 30 & 73,03 & \multirow{2}{*}{0,000} \\
\cline { 1 - 2 } Kontrol & 30 & 66,27 & \\
\hline
\end{tabular}

Pada tabel tampak hasil uji statistik didapatkan bahwa Sig 0,000 < 0,05 maka H0 ditolak, dan kesimpulanya adalah ada perbedaan yang signifikan pelaksanaan patien safety sesudah diberlakukan intervensi, pada kelompok intervensi \& kelompok kontrol.

\section{Tabel 4. Distribusi Capaian Skor Pelaksanaan Patien Safety Pada Kelompok Intervensi dan Kelompok Kontrol.}

\begin{tabular}{lllrr}
\hline Pengukuran & Kelompok & Mean & \multicolumn{1}{c}{$\begin{array}{c}\text { Std. } \\
\text { Deviation }\end{array}$} & N \\
\hline Pengukuran Pertama & Intervensi & 69,67 & 7,635 & 30 \\
\cline { 2 - 5 } & Kontrol & 70,00 & 7,978 & 30 \\
\cline { 2 - 5 } & Total & 69,83 & 7,744 & 60 \\
\hline Pengukuran Kedua & Intervensi & 73,97 & 4,657 & 30 \\
\cline { 2 - 5 } & Kontrol & 67,83 & 8,879 & 30 \\
\cline { 2 - 5 } & Total & 70,90 & 7,679 & 60 \\
\hline Pengukuran Ketiga & Intervensi & 73,27 & 4,785 & 30 \\
\cline { 2 - 5 } & Kontrol & 68,10 & 9,163 & 30 \\
\cline { 2 - 5 } & Total & 70,68 & 7,701 & 60 \\
\hline Pengukuran Keempat & Intervensi & 73,03 & 5,430 & 30 \\
\cline { 2 - 5 } & Kontrol & 66,27 & 7,570 & 30 \\
\cline { 2 - 5 } & Total & 69,65 & 7,369 & 60 \\
\hline
\end{tabular}

Distribusi rata-rata pencapaian kompetensi pengukuran ke-1 pada kelompok intervensi menunjukan skor rata-rata sebesar 69,67 dengan standar deviasi 7,635 sedangkan pada kelompok kontrol menunjukan skor rata-rata sebesar 70 dengan standar deviasi 7,978. Pencapaian kompetensi pengukuran ke-2 pada kelompok intervensi menunjukan skor rata-rata sebesar 73,97 dengan standar deviasi 4,657 sedangkan pada kelompok kontrol menunjukan skor rata-rata sebesar 67,83 dengan standar deviasi 8,879. Pencapaian kompetensi pengukuran ke-3 pada kelompok intervensi menunjukan skor rata-rata sebesar 73,27 dengan standar deviasi 4,785 sedangkan pada kelompok kontrol menunjukan skor rata-rata sebesar 70,68 dengan standar deviasi 9,163. Pencapaian kompetensi pengukuran ke-4 pada kelompok intervensi menunjukan skor rata-rata sebesar 73,03 dengan standar deviasi 5,430 sedangkan pada kelompok kontrol menunjukan skor rata-rata sebesar 66,27 dengan standar deviasi 7,570. 


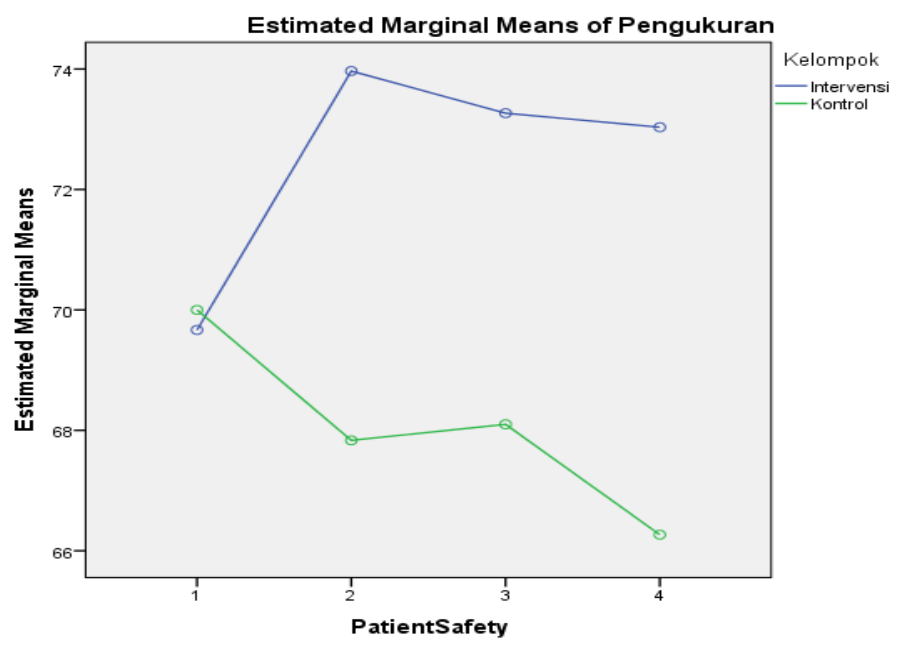

Grafik rata-rata pencapaian skor pelaksanaan sasaran keselamatan pasien antar kelompok menunjukan perbedaan yang signifikan. Pada kelompok intevensi pencapaian skor pelaksanaan patient safety lebih maksimum dibandingkan dengan kelompok kontrol. Pada kelompok intervensi pencapaian skor mulai menunjukan peningkatan dan maksimum mulai dari pengukuran ke 2. Hasil tersebut memperlihatkan bahwa pelatihan perawat islami yang dilakukan di ruangan cukup potensial dalam pencapaian pelaksanaan Patient safety dengan waktu yang lebih singkat dibandingkan dengan ruangan yang belum menerapkan pelatihan tersebut. maka kesimpulanya adalah pelatihan tersebut harus diberikan lebih dari satu kali.

\section{Pembahasan}

Hasil uji statistik didapatkan bahwa Sig 0,011 < 0,05 maka H0 ditolak, dan kesimpulanya adalah ada perbedaan yang signifikan pelaksanaan patient safety sebelum \& setelah diberlakukan intervensi pada kelompok intervensi.

\section{Uji perbedaan pelaksanaan sasaran keselamatan pasien, sesudah \& sebelum intervensi pada kelompok intervensi \& kelompok kontrol.}

Hasil uji statistik didapatkan bahwa Sig $0,000<0,05$ maka H0 ditolak, dan kesimpulanya adalah ada perbedaan yang signifikan pelaksanaan patient safety sesudah diberlakukan intervensi, pada kelompok intervensi \& kelompok kontrol.

Dalam intervensi melalui pelatihan keperawatan islami yang menamkan nilai

a. Professional yang di dalamnya terkandung pesan bahwa Keperawatan islami mengutamakan bekerja dengan cerdas, dan dilandasi ilmu sesui dengan Al-Quran Surat Al _mujadllah: 11 “ Niscaya allah akan meninggikan orang-orang diantaramu dan orang-orang yang berilmu pengetahuan beberapa derajat".

b. Ramah menuntun bekerja dengan muka cerah, senyum, komunikasi yang baik, sikap yang menyejukkan. " sesungguhnya jika kamu tidak menolong mereka dengan hartamu, 
maka (dapat juga) kamu menolong mereka dengan muka berseri dan pekerti yang baik". ( HR.abu Ya'la)

c. Amanah mengembangkan sifat : jujur, bertanggung jawab, terpecaya “ sesungguhnya Allah memerintahkan kamu sekalian untuk menunauikan anamat kepada Ahlinya". (QS. An-Nisa :58)

d. Istiqomah mengajarkan bekerja dengan sungguh sungguh, konsisten, komitmen tinggi, bekerja keras, ulet, tidak menegenal lelah, yang sesuai dengan salah satu sifat Rasul Allah SAW.

e. Sabar mengajarkan bekerja dengan tenang, tidak tergesa gesa, tetapi cepat dan tepat, terus berupaya saat tawakal, sabar tidak berarti lamban, innallaha ma'ashobirin (sesungguhnya Allah menyukai orang yang sabar)

Firman allah : Hai orangorang yang beriman, jadikanlah sabar dan shalat sebagai penolongmu, Sesungguhnya Allah beserta orang-orang yang sabar. (Q.S. Al Baqarah ayat 153)

Sabar adalah menahan diri ataupun menyiapkan diri untuk tidak mudah terganggu, tidak mudah tergoda dan tidak mudah dibawa kemanapun tanpa kejelasan. Maka di dalam menghadapi suatu ujian dan cobaan serta kesabaran ada tiga hal, sabar dalam menunaikan ibadah, sabar dalam menghadapi musibah dan sabar dalam menjauhi maksiat seseorang bisa di katakan sabar apabila dalam kehidupannya dia tidak selalu merasa menyesal, dalam hidupnya dia selalu memandang ke arah kemajuan(positive thinking), karena seseorang yang di limpahkan keimanan akan selalu meyakini janji
Ciptaan disebarluaskan di bawah Lisensi Creative Commons AtribusiNonKomersial-BerbagiSerupa 4.0 Internasional. Internasional.

Allah untuk selalu bersabar, sebagaimana janji-Nya dalam akhir surat Az-Zumar ayat 10:

"Sesungguhnya hanya orang-orang yang bersabarlah yang dicukupkan pahala mereka tanpa batas".

Dalam surat lain, Allah dengan indah menggambarkan bahwasanya orang-orang yang kelak mendapatkan keberkatan yang sempurna yaitu mereka yang masuk ke dalam kategori ayat ini:

Dan sungguh akan Kami berikan cobaan kepadamu, dengan sedikit ketakutan, kelaparan, kekurangan harta, jiwa dan buahbuahan. dan berikanlah berita gembira kepada orang-orang yang sabar. (yaitu) orang-orang yang apabila ditimpa musibah, mereka mengucapkan: "Inna Lillaahi Wa Innaa Ilaihi Raaji'uun"

Pujian Allah bagi orangorang yang sabar Sebagaimana yang terdapat dalam Al-Baqarah akhir ayat 177: “...Dan orang-orang yang bersabar dalam kesulitan, penderitaan dan dalam peperangan. Mereka itulah orang-orang yang benar imannya dan mereka itulah orang-orang yang bertaqwa."

Ihklas Bekerja harus ihklas, jangan terpaksa, Al 'amalu bi niyah (setiap pekerjaan dinilai sesuai niatnya ) (al hadist). Bekerja dengan niat ihklas akan mendapatkan pahala dan bila tidak ikhlas tidak berpahala " Dan tidaklah mereka disuruh, kecuali supaya menyembah Allah dengan mengkhilaskan kataatan kepadaNya dalam menjalankan Agama dengan lurus" (QS al Bayyinah : 5) "Padahal mereka tidak disuruh kecuali supaya menyembah Allah dengan memurnikan ketaatan 
kepada-Nya dalam (menjalankan) agama”. (QS. Al Bayyinah : 5)

HR Ahmad: Rasulullah shallallahu 'alaihi wa sallam bersabda, "Sesungguhnya sesuatu yang paling aku takutkan terjadi pada kalian adalah syrik kecil", para sahabat bertanya : "Wahai Rasulullah, apa itu syirik kecil? Rasulullah menjawab : "Riya".

HR.

Bukhari

"Sesungguhnya setiap amalan harus disertai dengan niat. Setiap orang hanya akan mendapatkan balasan tergantung pada niatnya. Barangsiapa yang hijrah karena cinta kepada Allah dan Rasul-Nya maka hijrahnya akan sampai kepada Allah dan Rasul-Nya. Barangsiapa yang hijrahnya karena menginginkan perkara dunia atau karena wanita yang ingin dinikahinya, maka hijrahnya (hanya) mendapatkan apa yang dia inginkan."

Menurut peneliti nilai nilai yang terkandung dalam keperawatan islami membuat individu bahwasanya bekerja harus dengan hati yang mengorientasikan apa yang dilakukan hanya untuk ibadah tunduk rukuk sujud hanya kepada allah, dengan pemahaman yang begitu maka setiap individu menpunyai tanggung jawab terhadap apa yang dilakukan dan dilaksanakan karena segala apa yang dilakukan di awasi oleh allah dan akan diminta pertanggung jawabkannya di akhirat kelak.

\section{Kesimpulan}

\author{
Berdasarkan hasil penelitian, \\ diperoleh kesimpulan :
}

1. Ada perbedaan yang signifikan kelompok intervensi sebelum dan sesudah dilakukan pelatihan dengan nilai $p$ value $0,000<0,05$ )

2. Karakteristik responden pada rentan usia dewasa dan sebagian besar berpendidikan D3 yaitu sebesar 73,3\% pada kelompok intervensi dan kelompok control.

3. Terdapat peningkatan Pada kelompok intevensi pencapaian skor pelaksanaan patien safety lebih maksimum dibandingkan dengan kelompok kontrol. Pada kelompok intervensi pencapaian skor mulai menunjukan peningkatan dan maksimim mulai dari pengukuran ke 2 setelah dilakukan pelatihan.

4. Terdapat hasil Pelatihan keperawatan islami yang dilakukan cukup potensial dalam pencapaian pelaksanaan patien safety dengan waktu yang singkat.

\section{Saran}

1. Bagi Pendidikan Keperawatan.

Masukan untuk Institusi pendidikan keperawatan agar memberikan kemampuan kepada mahasiswa keperawatan untuk dapat melakukan atau menerapkan keperawatan islami dalam melakukan asuhan keperwatan terhadap pasien di Rumah Sakit.

2. Bagi Peneliti Selanjutnya

Peneliti selanjutnya dapat mengembangkan penelitian dengan mempertimbangkan pendampingan selama intervensi sehingga mendapatkan hasil yang maksimal.

3. Bagi Pelayanan Kesehatan.

Bagi rumah sakit dapat menerapkan kebijakan tentang standar pelatihan keperwatan islami dalam upaya peningkatan pelayanan dan bisa 
JURNAL ILMU KESEHATAN BHAKTI HUSADA:

HEALTH SCIENCES JOURNAL, Vol. 09 No. 01, JUNI 2018

DOI: https://doi.org/10.34305/jikbh.v9i1.57

dilakukan secara teratur dan dilakukan supervisi dan monitoring sehingga keberjalanan program bisa lebih masimal.

4. Bagi Perawat
Ciptaan disebarluaskan di bawah Lisensi Creative Commons AtribusiNonKomersial-BerbagiSerupa 4.0 Internasional. Internasional.

Perawat dapat meningkatkan kompetensi dalam pelayanan keperwatan islami secara istiqomah dan terus elaksanakan tanpa dan adanya supervisi dari atasan.

\section{Daftar Pustaka}

Agustian, A.G. (2009). Rahasia Sukses membangkitkan ESQ Power: Sebuah inner Journey melalui Al. Ihsan. Jakarta: Arga Publishing.

H , Alimul. Azis., \& Uliyah Musrifatul. (2012) Buku Ajar Kebutuhan Dasar Manusia. Dalam Moh Wildan. Surabaya: Health Books Publishing.

Palit,Denise. F., \& Cheryl Tatang Beck. (2005) Nursing Research Principles and Metods (7th edition). Philadelphia: Lippincott.

M, Dewi. (2012). Pengaruh pelatihan timbang terima pasien terhadap penerapan keselamatan pasien oleh perawat pelaksana di RSUD Raden Mattaher Jambi. Jurnal Health \& Sport, Vol. 5, No. 3.

Hamid, A. Yani . (2005) Buku Ajar Spiritual Dalam Keperawatan. Jakarta: Widya Medika.

Ikram. (2013) Jurnal Hubungan Karakteristik Pasien Dengan Kualitas Pelayanan: Persepsi Pasien Pelayanan Rawat Inap RSUD Majene.

Ilhamsyah. (2010) Hubungan Pelaksanaan Keperawatan Spiritual Terhadap Kepeuasan Spiritual Pasien di Rumah SakitIbnu Sina Makasar, Fakultas Kedokteran, Manajemen Ilmu Keperawatan Universitas Hasanudin.

A, Izzan. (2010) Sakitku Ibadahku; Panduan Ibadah bagi pasien, keluarga pasien, dokter, dan perawat ; agar sakit selalu bernilai ibadah. Jakarta: Klinikal Mahira.
Kinasih., \& Wahyuningsih. (2012). Peran Pendampingan Spiritual Terhadap Motivasi Kesembuhan Pada Pasien Lanjut Usia. Jurnal Stikes Volume 5, No.1.

N., Laksono.I. (2008) Analisis Kepuasan Dan Hubungannya Dengan Loyalitas Pasien Rawat Inap Di Rumah Sakit Dedi Jaya Kabupaten Brebes, Program Pasca Sarjana, Universitas Diponegoro (tidak dipublikasikan).

W., Lim.J. \& Yi, J. (2009). The Effects of religiosity, Spirituality, and Social Support an Quality of Life: A Comparison between Korean American and Korean Breast and Gynecologic cancer survivars. Jurnal oncology nursing forum. Vol.36 (6).699.

K., Mauk.L. \& Schmidt, NK. (2005). Spiritual Care in Nursing Practice. Philadelphia: Lippicott Williams \& Wilkins.

Nanda International. Diagnosis Keperawatan; Definisi dan klasifikasi. Alih Bahasa; Made Saraswati, Dwi widiarti, dan Estu Tiar. Jakarta: Penerbit Buku Kedokteran EGC. 2011

Nursalam. (2011). Konsep \& Penerapan Metodologi Penelitian Ilmu Keperawatan: Pedoman Skripsi, Thesis dan Instrumen Keperawatan. Edisi 2. Jakarta: Salemba Medika.

Nursalam. (2011). Manajemen Keperawatan Aplikasi dalam Praktek Keperawatan Profesional (Edisi 3) Jakarta: Salemba Medika. 
JURNAL ILMU KESEHATAN BHAKTI HUSADA:

HEALTH SCIENCES JOURNAL, Vol. 09 No. 01, JUNI 2018

DOI: https://doi.org/10.34305/jikbh.v9i1.57

Nurwahidah. (2013). Hubungan Kepuasan Pasien Terhadap Bimbingan Ibadah Pasien Dengan Motivasi Sembuh di RS Islam Darrussalam: Fakultas Keperawatan Universitas Padjajaran.

As'ad, Patima dan Saleh A. 2013. Hubungan Kepuasan Pasien Berdasarkan Dimensi Pelayanan Keperawatan. Word Of Mouth di Ruang Rawat Inap Rumah Sakit Islam Faisal Makassar.UIN Alauddin Makasar. (Tidak dipublikasikan)

Is, Pohan. 2017. Jaminan Mutu Layanan Kesehatan. Dasar- dasar pengertian dan penerapan. Jakarta. Kedokteran EGC

Potter \& Perry AG. ( Y. Asih, M. Sumarwati, D. Evriyani, L. Mahmudah, Ellen. P., Kusrini, Sari, K., E. Novie Astari, Penerjemah ). 2005. Ajar Fundamental Keperawatan. Konsep, Proses, dan Praktik. Jakarta. EGC. ( Buku Asli dipublikasikan 1997 )

N, Prastiwi E \& Ayubi D. 2008. Hubungan Kepuasan Pasien Bayar Dengan Minat Kunjungan Ulang Di Puskesmas Wisma Jaya Kota Bekasi Tahun 2007. Makara, Kesehatan, Vol. 12, No. 1: 4246.

Inggriane, Puspita. 2009. Aplikasi Asuhan Keperawatan Spiritual Muslim. Di R. Firdaus Iii Rs. Al-Islam Bandung. Jurnal Unpad. Volume 11 No. XX Maret 2009 - September 2009 Hal - 60
Ciptaan disebarluaskan di bawah Lisensi Creative Commons AtribusiNonKomersial-BerbagiSerupa 4.0 Internasional. Internasional.

Rohman. 2009. Faktor - faktor yang berhubungan dengan pemberian asuhan spiritual oleh perawat di RS Islam Jakrta. Tesis Fakultas Ilmu Keperawatan Universitas Indonesia ( FIK. UI ). (Tidak dipublikasikan).

S, Sastroasmoro \& Ismael, S. 2008. Dasar - dasar Metodologi penelitian Klinis. Jakarta. Edisi 3.: CV. Sagung Seto.

Setiadi. 2007. Konsep \& Penulisan Riset Keperawatan.Yogyakarta. Graha Ilmu.

Notoatmodjo, Soekidjo. 2012. Metodologi Penelitian Kesehatan. Jakarta. Rineka Cipta Edisi Revisi Cetakan II.

Dahlan, Sopiyudin. 2012. Statistik Untuk Kedokteran dan Kesehatan. Jakarta. Salemba Medika.

Sugiyono. 2004. Statistik Untuk Penelitian. Bandung. Alfabeta.

C, Triwibowo. 2012. Perizinan dan Akreditasi Rumah Sakit Sebuah Kajian Hukum Kesehatan, Yogyakarta, Nuha Medika.

Utami, 2009. Hubungan Antara Pengetahuan dengan Sikap Perawat dalam Pemenuhan Kebutuhan Spiritual Pasien. di RSUD Sukoharjo, Jurnal Berita Ilmu Keperawatan,

LM, Wright. 2005. Spirituality, Suffering, and Illness Ideas for Healing. Philadhelphia; F.A. Davis Company.

C, Young. \& Koopsen, C. 2007. Spiritualitas, Kesehatan, dan Penyembuhan. Medan Bina Media Perintis. 